\title{
Deus, marido, patrão e colono: uma estética para a sublevação
}

\author{
God, busband, boss and settler: an aesthetic for the uprising
}

Resumo: Partindo do livro Novas Cartas Portuguesas (1972), de Maria Isabel Barreno, Maria Teresa Horta e Maria Velho da Costa, em que o elemento feminino desafia os valores patriarcais da ditadura salazarista, pretende-se mostrar as similaridades entre colonialismo e exploração de género, tendo como pano de fundo a ditadura em Portugal. A obra incita e denuncia as opressões não só ao nível do género, mas também ao nível de todas as classes oprimidas, incluindo as opressões decorrentes durante a guerra colonial, tema tabu durante o regime ditatorial. Iremos assim mostrar de que forma esta obra, que motivou o primeiro caso feminista internacional, é um convite não à sublevação de género, mas à de todas as classes oprimidas.

Palavras-chave: Novas Cartas Portuguesas, colonialismo, exploração de género, equiparação, binómios

\begin{abstract}
Starting from the book Novas Cartas Portuguesas (1972), by Maria Isabel Barreno, Maria Teresa Horta and Maria Velho da Costa, in which the feminine element challenges the patriarchal values of the Salazarist dictatorship, we intend to show the similarities between colonialism and gender exploitation, in the context of the Portuguese dictatorship. This literary work incites and denounces oppressions not only as far as gender is concerned but also as far as all the oppressed classes are concerned, including those that arose during the colonial war, a taboo during the dictatorial regime. We will thus show how this work, which motivated the first international feminist case, is an invitation not to the uprising of gender, but to that of all the oppressed classes.
\end{abstract}

Keywords: Novas Cartas Portuguesas, colonialism, gender exploitation, equalization, binomials.

\section{INTRODUÇÃO}

Em 2007, veio a público um documentário de guerra dirigido por Lisa F. Jackson. Intitulado "The Greatest Silence: Rape in the Congo", o filme de 76 minutos mostra as violações a que as mulheres do Congo e do Ruanda estão sujeitas. Sem esconder a crueza e a crueldade, o documentário mostra-nos uma guerra que, como dirá uma congolesa, é feita entre os homens e contra as mulheres, violadas por soldados. Os violadores, por sua vez, verão na violação "uma magia para vencer a guerra" e afirmam claramente a crença na sua superioridade: Deus terá feito as mulheres inferiores para que pudessem ser tomadas à vontade. Dispor delas não é, assim, imoral ou condenável. Não é, por isso, algo que deva sequer ser escondido: um dos congoleses afirma peremptoriamente que, quando a mulher resiste aos seus avanços sexuais, ele não se coíbe de usar a força; se ela for forte, pede aos amigos que o ajudem a subjugá-la. A impunidade, numa zona em que os homens usam as armas para conseguirem o que querem, é o sustento das violações. Partiremos para este estudo com esta ideia, mostrando de que forma a opressão de género se

* Doutorada em Ciências Humanas, mestre em Estudos Portugueses, pós-graduada em Linguística, licenciada em Línguas Aplicadas. E-mail: anabarbarapedrosa@gmail.com. 
assemelha à violência do colonialismo, uma vez que a violência machista é ainda usada em práticas de colonização e, frequentemente, como arma de guerra.

Novas Cartas Portuguesas (1972), de Maria Isabel Barreno, Maria Teresa Horta e Maria Velho da Costa, o objecto deste estudo, não foi um mero exercício retórico: a obra tem um claro propósito político, dando um contributo importantíssimo para as teorias feministas e incentivando as práticas de igualdade de género. Mapeando as inúmeras agressões de género, datadas e localizadas, as autoras inscreveram-se numa luta que ainda não conheceu fim.

Com o estudo do próprio género, as autoras, conscientes de uma herança histórica negativa para o sexo feminino, apetrecharam-se com uma ferramenta fundamental para a análise das relações de poder entre os géneros: uma consciência intelectual crítica que lhes forneceu uma capacidade analítica crucial para a criação de uma obra política com capacidade de agitar, expondo um sistema ideológico que legitimava a violência contra as mulheres.

\section{DEUS, MARIDO, PATRÃO E COLONO}

Na obra Couro imperial (2010), Anne McClintock consegue ligar as explorações de género, de raça e de classe, tendo como cenário o imperialismo britânico. Desta forma, faz uma ponte entre colonização e exploração de género: ao longo do texto, equipara a imagem da mulher às terras por desvendar, do ponto de vista do colonizador, e explorar, ao nível de recursos humanos e materiais. É nesse sentido que a colonização aparece também como chauvinismo masculino: a terra encarna a figura da fêmea, submissa, pronta a entregar-se. Assim, a autora dá o exemplo de uma obra de Jan van der Straet, em que o "descobrimento" da América encarna numa relação erótica entre um homem e uma mulher. A indígena, desprovida de roupa, ao contrário do colonizador, insinua sexo da sua posição submissa. Vemos, assim, que as práticas de conhecimento e exploração do mundo acompanhavam as da violência de género, por meio da propriedade privada e do individualismo possessivo. McClintock refere-se ainda ao reenquadramento do mundo por parte dos colonizadores, que o rearranjavam de acordo com os interesses dos seus poderes imperiais. É nesse sentido que, mais tarde, irá referir-se ainda aos mapeamentos, que estariam ao serviço da pilhagem colonial, uma vez que legitimavam a conquista da terra (MCCLINTOCK, 2010: 53). Ao fantasiarem o mundo, encarnando-o no feminino e expondo-o à exploração masculina, superariam a exploração dos binómios homemmulher e colonizador-colonizado, antes arquitectando relações de poder mais complexas que derivavam de várias identidades sociais. A fantasia do mundo no feminino daria ainda à mulher $\mathrm{o}$ estatuto de pessoa/terra frágil, convidando à pilhagem colonial. Posteriormente, a autora refere-se ainda ao mito da terra virgem, que permitiria a exploração dos colonizadores, uma vez que uma terra virgem não poderia ser reivindicada (MCCLINTOCK, 2010: 57). Com isto, a mulher encontrar-se-ia naturalmente fora do sistema político.

Na obra Novas Cartas Portuguesas, as autoras fizeram uma representação literária 
muito abrangente da condição feminina em Portugal no quadro da ditadura salazarista. Assim, aliaram a exploração de género à classista, mostrando as várias posições, sempre submissas, que as mulheres ocupavam na sociedade, questionando não só a desigualdade de géneros, mas toda uma ordem social. De mulheres confinadas ao espaço doméstico a mulheres encarceradas em conventos ou violentadas, todas as atrocidades existentes naquela sociedade patriarcal tiveram representação literária. As autoras mostraram ainda como a subjugação sexual funcionava como garantia de poder.

Citando Descartes, McClintock mostra ainda de que forma se casaram a violência de género com a propriedade privada: a conquista imperial das terras teria de ser feita através da subordinação das mulheres enquanto categoria da natureza. Tal não só permitiria que todas as atrocidades - roubos, violações, assassinatos - fossem permitidas aos colonizadores como ainda as tornaria necessárias, uma vez que os povos que ocupavam as terras que estavam, do ponto de vista dos colonizadores, por descobrir teriam de ser deslocados para aquilo a que a autora chama de "espaço anacrónico" (MCCLINTOCK, 2010: 58), ocupado por gente atávica, irracional, desumana, que encarnaria o "primitivo". McClintock vai referir-se ainda àquela que seria uma erótica do alumbramento e da conquista: o mundo representava o feminino e estaria espacialmente exposto para a exploração masculina. A partir daí, estaria à mercê do poder imperial, que veria na subordinação das mulheres uma categoria da natureza (MCCLINTOCK, 2010: 47). Desta forma, a erótica da conquista imperial era principalmente uma erótica da subjugação feminina. Cabe ainda dizer que a vinculação entre sexo e subjugação faz parte de um imaginário patriarcal que naturaliza a instrumentalização das mulheres para produção do prazer masculino.

Stolcke nota ainda que o que motivava a empresa colonial eram o lucro pessoal e a riqueza nacional. Assim sendo, a colonização foi o resultado de um empreendimento político e económico que passou pela exploração de recursos humanos e naturais nos territórios a colonizar (STOLCKE, 2006, p. 18). Desta forma, as populações locais foram submetidas a trabalhos forçados, os recursos naturais foram explorados e as mulheres indígenas passaram por todos os abusos sexuais. A violação é, aliás, uma arma de guerra altamente eficaz: destrói psicologicamente metade da população, funciona como uma poderosíssima chantagem e forma de intimidação, espraia doenças, permitindo a diminuição da população colonizada, e não tem qualquer custo monetário. Com tudo isto, registaram-se mais de 15 mil violações em 2009 só no Leste da RD Congo, onde tal arma é usada de forma massiva. Darcy Ribeiro, referindo-se à colonização do Brasil, vai ainda sublinhar que os colonos tomavam (ou seja, violavam), "como era uso na terra", tantas índias quantas pudessem (RIBEIRO, 2013: 79). O mesmo se passaria com o território: quanto mais fosse explorado, maior era o poder de quem explorava. A exploração dos corpos das mulheres também era, como vimos, uma forma de aumentar não somente o poder masculino, mas o poder - principalmente económico e social - de quem colonizava. Encontrava-se ali, portanto, uma opressão, em simultâneo, de várias classes, uma vez que a opressão de género, funcionando como arma de guerra, se tornava principalmente numa arma de exploração económica e social.

É ainda importante notar o processo de classificação inerente à vida social e, aqui 
concretamente, à colonização e à dominação masculina. Esse processo consiste sempre numa divisão de sujeitos entre "nós" e "eles", baseando-se em critérios de identificação e de diferença. Dessa forma, as classificações nascem da criação de identidades colectivas que resultam na determinação de hierarquias. Naturalmente, o privilégio da classificação pertencerá às classes dominantes, que atribuem diferentes valores aos diferentes grupos, mantendo-se sempre no lugar social privilegiado, fruto da sua relação de poder e da sua necessidade de perpetuá-lo. A identidade e a diferença serão, assim, criações sociais e culturais (SILVA, 2000, p. 76), resultantes de um processo de produção simbólica e discursiva (SILVA, 2000, p. 81). Para diferenciar, convém ainda naturalizar a classe diferenciada. Neste sentido, Ferreira e Hamlin (2010) mostraram de que forma, na história do pensamento ocidental, mulheres, negros e monstros roçam o desalmado: os três são representados como estando mais próximos do estado natural, configurando a essência liminar da sua humanidade e sugerindo que um espaço de civilização que se contraponha a essa proximidade tem de ser forjado (FERREIRA; HAMILIN, 2010, p. 811-812). Desta forma, a constituição da sociedade moderna terá sido o resultado de monstruosas imagens de alteridade. Assim, o monstruoso aparecerá como lugar da alteridade por excelência, um lugar que marca a fronteira entre civilização e barbárie (FERREIRA; HAMLIN, 2010, p. 812). Daí a visão dos colonos sobre os índios: eles seriam um gado humano cuja natureza, mais próxima de bicho que de gente, os encaminharia para a escravatura (RIBEIRO, 2013, p. 49). Por sua vez, e de acordo com esta visão, a misoginia aparece não como ódio irracional, mas como uma mera técnica retórica que tem o objectivo de construir o homem, ao elevá-lo à categoria de modelo ideal (BRAIDOTTI, 2004, p. 12). O corpo é, assim, objecto de relações sociais de poder.

Para podermos entender de que forma esta relação colonialismo/opressão de género se faz sentir na obra Novas Cartas Portuguesas (1972), convém ainda ter em conta a forma como Milton Santos inovou o modo de pensar a geografia, ao considerar que é o uso do território, ao invés do território per se, que o torna em objecto de análise social. Assim, entender o território é um passo fulcral no afastamento do risco de alienação (SANTOS, 2005, p. 255). Parte dessa importância residirá no facto de estar intimamente ligado ao processo de produção. Veremos aqui de que forma os corpos das mulheres se assemelharam ao território, sendo ambos usados e explorados das mesmas formas.

\section{DO LUGAR SOCIAL À PRODUÇÃO LITERÁRIA}

As autoras de Novas Cartas Portuguesas souberam aliar a exploração de género à exploração territorial, não estando nunca indiferentes aos paralelismos das explorações. Daí que tenham representado literariamente a mulher como colónia do homem, uma vez que a relação estabelecida na colonização é já de pura exploração: o colonizador tem tudo à sua mercê e explora o território como lhe aprouver, servindo-se dos seus recursos e das suas gentes, vistas como desumanas e atávicas. O espaço da colonização é, assim, um espaço sem leis onde tudo pode acontecer em prol de quem coloniza. Ao mapear o território, o colonizador assume-o e legitima-o já como seu. Numa passagem da obra literária que aqui tratamos, a percepção destes paralelismos de opressões marca presença 
de forma peremptória: "Porque só de minha posse na verdade te importas: eu tua terra, colónia, tua árvore-sombra-programada para acalmar sentidos. Também em ti me queres de clausura, tu próprio meu convento, minha única ambição, afinal meu único deserto." (BARRENO; HORTA; COSTA, 2010, p. 21). A mulher seria, assim, vista como propriedade privada do homem, colónia dele, posta totalmente à sua mercê e à sua exploração (numa parte de Novas Cartas Portuguesas, um soldado escreve uma carta a um amigo, transitando da ideia de transação de propriedade para a relação que tem com a namorada, vista como objecto transacionável). Assim, também a mulher será terreno sem lei, uma vez que a violência sobre ela exercida era, à hora da escrita dos textos que compõem a obra, mantida no sigilo da vida privada, não sendo nunca considerada um assunto político (a violência doméstica só se tornaria um crime público, em Portugal, no ano 2007). É também aí que esta obra inova: ela permite que o reflexo do social no pessoal possa partir para o discurso político público.

Escrevendo sobre a segunda fase do feminismo no Brasil, Nancy há-de notar que, por ter negligenciado os desdobramentos político-económicos e geopolíticos, ela não pôde opor-se às políticas do neoliberalismo, uma vez que se encontrava no âmbito da política de identidades (NANCY, 2007, p. 293). As autoras de Novas Cartas Portuguesas, contudo, não caíram nesse erro: numa só obra literária, aliaram as opressões de género às opressões de classe e às que advinham da guerra colonial, denunciando várias das práticas repressivas do regime ditatorial português. $\mathrm{O}$ feminismo era, assim, reinventado enquanto projecto político, enquadrado nas várias relações de poder sob as quais estava erigida a sociedade.

Tal visão do feminismo estará de acordo com as de Mara Lago (2004) e de Maria Luísa Femenías (2007). Mara Lago, articulando indivíduo e sociedade, rejeita a ideia de indivíduo uno e indivisível, interpretando-o sempre à luz do seu contexto social. Dessa forma, o meio envolvente não será externo ao indivíduo, que se socializa à medida que internaliza as influências externas (Lago, 2004, p. 74). Assumindo que a cultura antecede e constitui o sujeito enquanto indivíduo, ao invés de meramente ser-lhe acrescentado, a autora considera-o um organismo nascido em contexto social, histórico e imerso na cultura. Nesse sentido, considera-o "assujeitado" (LAGO, 2004, p. 74). A autora refere-se ainda a uma classificação das identidades habitual de teóricos, que as dividem em dicotomias como pessoal/social e individual/cultural, enfatizando a oposição indivíduo/sociedade, o que expulsaria o primeiro da cultura, como se fosse independente dela, externo a ela, e, portanto, ininteligível. Chamando a atenção para as semelhanças entre os processos de construção de identidades pessoais e culturais (LAGO, 2004, p. 75), a autora considerará que a identidade é uma construção imaginária (LAGO, 2004, p. 75), uma vez que se constrói nas relações de contraste. Femenías, por sua vez, considera que as condições materiais devem somar-se ao marco formal e universalista (FEMENÍAS, 2007, p. 12). Assim, há-de ainda invocar o seu lugar social para poder dar uma resposta política ao problema do chauvinismo masculino: defendendo que a resposta apela ao locus e ao ubis da condição geo-sociopolítica, há-de entender que a real contribuição para o discurso feminista passa pela experiência crítica das agentes (FEMENÍAS, 2007, p. 14). O conhecimento localizado será, assim, a única forma de ultrapassar barreiras materiais que 
impeçam a estratégia política de vingar.

A experiência crítica a que a autora se refere foi, aliás, um dos maiores marcos do livro das três Marias: afirmando que lhes era imposto um lugar social ("Em salas nos queriam às três, atentas, a bordarmos os dias com muitos silêncios de hábito, muito meigas falas e atitudes" in BARRENO; HORTA; COSTA, 2010, p. 20), e recusando-o ("Mas tanto faz aqui ou em Beja a clausura, que a ela nos negamos, nos vamos de manso ou de arremesso súbito rasgando as vestes e montando a vida como se machos fôramos" in BARRENO; HORTA; COSTA, 2010, p. 20), elas puderam em primeira mão confrontar quem as lia com a realidade de um género oprimido. Dessa forma, essa realidade ganhou substância, ao emancipar-se do espaço privado, erigindo-se no público, com uma profundidade sem precedentes. Daí, aliás, que o livro tenha sido proibido meros três dias após a sua publicação: um livro que tão claramente desafiava os valores patriarcais - e as estruturas simbólicas sob as quais a sociedade se erigia, portanto - punha em causa uma ditadura que já tinha os presos políticos e a Guerra do Ultramar sobre os seus ombros. As autoras afirmam que esta "experiência de três" poderá, assim, não ser mais "do que o espremer de um furúnculo" em que são ditos "os mal-estares, os ataques, as recusas e os medos" (BARRENO; HORTA; COSTA, 2010, p. 288). Contudo, desvendando o que estava encoberto, enclausurado na vida privada, as autoras conseguiram lançar uma obra que incluía a ameaça da decomposição da legitimidade da violência machista.

O valor de uma obra literária não pode deduzir-se apenas das circunstâncias biográficas ou históricas ou até do lugar que ela ocupa na evolução num género; ao invés disso, deve deduzir-se também por meio de outros critérios: produção, recepção, influência exercida, valor reconhecido para a posterioridade (JAUSS, 1978, p. 24). A obra deve, desta forma, ser analisada enquanto o todo orgânico que nasce da fusão de diversos níveis de experiência (ECO, 1988, p. 28), importando particularmente o ponto de partida e o ponto de chegada dessa criação. Assim, importará aqui também a relação de alteridade, uma vez que é essa a que é estabelecida entre intérprete e obra. A arte, estruturando certo material, pode dirigir o seu discurso sobre o mundo e reagir à história da qual nasce, interpretando-a, julgando-a, fazendo projectos (ECO, 1988, p. 33). Ao mesmo tempo, sendo criadora de realidade, os seus efeitos no campo político e nas práticas sócioculturais podem ser analisados (LOPES, 2010, p. 52).

A recepção cultural engloba a interpretação como um acto de um processo estético que inclui toda uma cadeia de construção, difusão e reconstrução dos textos (LOPES, 2010, p. 51). Assim, a importância de Novas Cartas Portuguesas supera, por isso, e em muito, o seu valor literário: a obra vale essencialmente pelo ataque que constitui ao poder instituído. Foi, aliás, por ele que se tornou num caso mediático ao nível internacional e vale hoje principalmente pelo lugar único que ocupa nos movimentos feministas ocorridos em Portugal durante o século XX. Assim, importa, neste caso, o contexto em que a obra foi produzida, porque foi ele que permitiu que se estabelecesse a relação dialógica autoras-trabalho-público a que aqui fazemos referência. Deriva daqui a noção de Eco (1988) de obra em movimento, que consiste na possibilidade de uma multiplicidade de intervenções pessoais. Segundo ela, o/a autor/a oferece uma obra $a$ acabar e, ao terminar o diálogo interpretativo, por ter sido a sua obra aquela que foi objecto 
de análise, será a sua forma aquela que é atingida, ainda que organizada por outra (ECO, 1988, p. 62). O verdadeiro conteúdo da obra torna-se, assim, no seu modo de ver o mundo e de julgá-lo, traduzindo-se em modo de formar, já que é nesse nível que deverá ser conduzido o discurso sobre as relações entre a arte e o mundo (ECO, 1988, p. 258). A obra de arte será, assim, ainda que fechada na sua perfeição de organismo calibrado, aberta, já que é passível de múltiplas interpretações, não redundando isto na alteração da sua singularidade irreproduzível (ECO, 1988, p. 41). Assim, o processo estético que norteou a escrita das três Marias seria inserido na cadeia que inclui a interpretação - e que, logo a após a publicação da obra, terminou em censura e, imediatamente a seguir, motivou um caso ímpar de mobilização internacional em torno de uma causa feminista.

\section{Novas Cartas Portuguesas: a tomada da palavra}

A escrita de Novas Cartas Portuguesas representou um misto de denúncia e de incitação à sublevação das mulheres. Com a obra, as mulheres, também enquanto personagens, teriam um papel até então pouco usual na literatura, até porque as autoras, assumindo um acesso à produção simbólica que lhes estava vedado a priori, deixavam de ser apenas matéria literária, tornando-se também em agentes literários. Foi por esse motivo que a obra foi tão perigosa para o regime ditatorial: à tomada da palavra por parte das mulheres, denunciando as opressões, incitando a sublevação e recusando o domínio, elas deram um primeiro passo para a alteração da relação de forças.

Iremos, neste subponto, referir-nos a algumas das cenas desta obra que nos mostram a forma como a mulher é vista como propriedade do homem, corpo a ser possuído e terra que lhe pertence: “(ah, mulher! que é para te comprar que eu trabalho há séculos, e minhas leis, e tu sempre me foges), corpo que se possui, terra do homem, carne da sua carne, costela de Adão" (BARRENO; HORTA; COSTA, 2010, p. 81/82). A visão do homem, enquanto classe dominante, legitimava esta visão e esta opressão, uma vez que detinha o privilégio da classificação e que, portanto, estava apto a atribuir diferentes valores sociais a diferentes grupos. Precisamente neste sentido, Pierre Bourdieu considera a dominação masculina um dos mais gritantes casos de discriminação simbólica, já que que a violência simbólica que as mulheres sofrem, tantas vezes invisível para elas mesmas, é essencialmente exercida através das vias simbólicas da comunicação (Bourdieu, 2012, p. 7). Em concomitância, o autor vai considerar que esse poder reside na forma como os dominantes fazem reconhecer a sua maneira de ser particular como universal (BOURDIEU, 2012, p. 78). Nesse mesmo sentido, Simone de Beauvoir refere-se à ideia do masculino como universal, representando tanto o positivo como o neutro (BEAUVOIR, 1970, p. 9). Estas ideias de violência simbólica e de masculino como universal são cruciais em estudos de género, uma vez que são as razões de fundo para as discriminações sofridas e que são elas que arquitectam o poder no masculino. Partindo daqui, a mulher é apresentada - e representada - como um ser imoral, numa mera técnica retórica de isentar e elevar o homem à categoria de modelo ideal. A misoginia não será, assim, um mero acto irracional de ódio às mulheres, antes sendo uma necessidade 
estrutural para a afirmação masculina (BRAIDOTTI, 2004, p. 12). Neste sentido, e como aponta Braidotti (2004), as mulheres são definidas por oposição aos homens, sendo-lhes atribuído um marco de inferioridade, que deverá ser visto como um traço natural. Por estes motivos, será só na posse que os homens podem ter interesse: "Porque só de minha posse na verdade te importas: eu tua terra, colónia, tua árvore-sombra-programada para acalmar sentidos. Também em ti me queres de clausura, tu próprio meu convento, minha única ambição, afinal meu único deserto».” (BARRENO; HORTA; COSTA, 2010, p. 21); "Mulher: abastança de homem, sua semelhança, sua terra, seu latifúndio herdado" (BARRENO; HORTA; COSTA, 2010, p. 75).

A utilização do sexo como arma de subjugação é muito evidente na obra. Assim, há uma cena em que uma mulher é forçada a manter relações com um homem que, por sua vez, não ignora nem o horror nem o nojo que lhe provoca: "Gosto que tenhas nojo mas que venhas comigo para a cama” (BARRENO; HORTA; COSTA, 2010, p. 191). Esta ideia remete-nos ainda para trabalhos de Bourdieu em que o autor interpreta a relação sexual como uma relação social de dominação, exercida sobre o feminino, que deve ser passivo. Dessa forma, o desejo masculino é visto como desejo de posse e o feminino como desejo de dominação masculina (Bourdieu, 2012, p. 31). Daí a indígena de Jan van der Straet, a que já fizemos referência: o homem/colono chega para possuir, a mulher/terra convida à posse, da sua posição submissa, e insinua, assim, uma tomada fácil, o que vai também de encontro à ideia de terra virgem, posta a ser tomada, uma vez que desprovida de dono. Desta forma, a relação sexual em forma de violação aparece, no âmbito da colonização, como uma manobra particularmente eficaz de subjugar. O mesmo se verifica na opressão de género tratada em Novas Cartas Portuguesas, em que há uma cena em que a violação serve precisamente para acentuar a relação hierárquica e em que o prazer masculino funciona como "vitória" (BARRENO; HORTA; COSTA, 2010, p. 193) sobre a mulher violada.

As autoras, na hora de escrita da obra, assumem a relação de colonialismo existente entre homens e mulheres. Desta forma, citam um texto em que é dito que "se diz por laracha que «a mulher é a última colónia do homem» (...). Se bem que aquela fórmula entre aspas seja excessiva e de mau gosto, exprime, no entanto, o facto de a condição profissional das mulheres estar ainda submetida a numerosas desigualdades" (BARRENO; HORTA; COSTA: 2010, p. 221). Ironizarão com a perspectiva de quem escreveu o texto, precisamente concordando com o paralelismo entre a colonização e as relações de poder entre género: "(por laracha, irmãs?) (...) (excessiva, irmãs?) (...) (claro, de mau gosto, irmãs...) (...) Colónia do homem, a mulher? Que ideia! Que exagero!...” (BARRENO; HORTA; COSTA, 2010, p. 221). As autoras mostram, com esta ordem, de que forma as relações de opressão são paralelizáveis, não distanciando umas de outras e não conseguindo isolá-las, o que renega os discursos de identidade a que já fizemos referência anteriormente. Assim, a obra refere-se a várias opressões, paralelizando-as colonialismo, machismo, exploração classista -, com a clara consciência de que, como disse Simone de Beauvoir, a mulher burguesa se solidariza com o homem burguês e não com a mulher proletária (BEAUVOIR, 1970, p. 13). Assim, será também, como claramente sugerido pela obra das três Marias, necessário ultrapassar a dominação classista 
também para se chegar à equidade de género. Desta forma, a obra, tendo as conta as várias estruturas de dominação, indicia que só a destruição de todas elas pode permitir um mundo em que a dominação masculina não seja uma realidade. Conhecido internacionalmente pelo seu cunho feminista, a obra, afinal, ultrapassa as paredes da exploração de género.

\section{Considerações finais}

Ao lançarem mãos a esta obra, as autoras empreenderam numa jornada que as tornaria num caso internacional mediático que ficaria conhecido como o primeiro caso feminista internacional. Pela escrita da obra, foram censuradas, perseguidas, levadas a tribunal e só não foram julgadas porque a queda da ditadura chegou para isentá-las. Talvez já pudessem prever o escândalo que o livro provocaria, uma vez que tinham noção de que ele abalava as relações de poder, denunciando-as e rejeitando-as como naturais, e que afirmavam que "a revolta da mulher é a que leva à convulsão em todos os extractos sociais; nada fica de pé, nem relações de classe, nem de grupo, nem individuais, toda a repressão terá de ser desenraizada, e a primeira repressão, aquela em que veio assentar toda a história do género humano, criando o modelo e os mitos das outras repressões, é a do homem contra a mulher." (BARRENO; HORTA; COSTA, 2010, p. 198). Assumem claramente essa revolta, rejeitando as humilhações de um "marido: dono, senhor" (BARRENO; HORTA; COSTA, 2010, p. 213). Cumprem, assim, o intento de agitar as convenções sociais.

Numa obra literária que, após ter sido proibida pela censura de Marcelo Caetano, se tornaria no primeiro caso feminista internacional, as autoras tiveram o arrojo de denunciar a situação em que viviam as mulheres. Fizeram-no através de dois tipos de personagens: umas quase coniventes com a repressão que se sofrem, sendo, como diria Sartre, metade vítimas, metade cúmplices, encarnando o papel a que estão destinadas pelos mecanismos da violência simbólica (Bourdieu, 2012); outras com capacidade analítica para entenderem os mecanismos de poder que forjam as relações de poder (tanto numas como noutras, ficaram ainda claras as opressões de classe). Desta forma, as autoras mostram que não são cegas aos mecanismos sociais do poder, afirmando que a "repressão perfeita é a que não é sentida por quem a sofre, a que é assumida, ao longo duma sábia educação, por tal forma que os mecanismos da repressão passam a estar no próprio indivíduo, e que este retira daí as suas próprias satisfações." (BARRENO; HORTA; COSTA, 2010, p. 198/199).

Numa obra que, ainda que prime pelo seu cunho feminista, alia e denuncia vários tipos de opressões, torna-se clara a equiparação da mulher às terras por colonizar: estas últimas, não raras vezes, são representadas em figuras de fêmeas prontas a entregar-se, prontas à posse. Desta forma, a colonização encarna numa relação erótica heterossexual, em que o papel submisso é invariavelmente aquele a ser desempenhado pelo feminino. Assim, a conquista imperial só podia efectuar-se através da subordinação das mulheres: 
ao considerá-las num estado de natureza mais distante do humano, uma vez que o homem era visto como o neutro, estaria permitido que todas as atrocidades fossem cometidas sobre elas. A erótica da conquista imperial seria, assim, uma erótica de subjugação feminina: através dela, o imaginário patriarcal pôde naturalizar a instrumentalização dos corpos femininos para aumentar e perpetuar a sua própria dominação. Daí que não tenha sido à toa que as autoras tenham escrito: "Porque só de minha posse na verdade te importas: eu tua terra, colónia, tua árvore-sombra-programada para acalmar sentidos. Também em ti me queres de clausura, tu próprio meu convento, minha única ambição, afinal meu único deserto»." (BARRENO; HORTA; COSTA, 2010, p. 21). Assim, assumese claramente o desejo de posse masculino - desejo esse que também assume o papel preponderante na acção dos colonos, que ambicionam a expansão e a exploração de recursos. Ambas serão, assim, reflexo do individualismo e do desejo da propriedade privada. Imaginar o mundo no feminino, disposto à pilhagem colonial e à dominação masculina, faz com que sejam superados os binómios homem-mulher e colonizadorcolonizado e com que se parta para um quadro de relações de poder mais complexo, resultante de várias opressões. As autoras de Novas Cartas Portuguesas ultrapassaram as barreiras de género e souberam aliar os vários tipos de opressões: assim, deixaram claro que a exploração de género não existe em si e por si. Pelo contrário, ela só deixa de existir quando outras opressões forem ultrapassadas, como a exploração classista.

\section{Referências bibliográficas}

BARRENO, Maria Isabel; HORTA, Maria Teresa; COSTA, Maria Velho da. Novas Cartas Portuguesas. Alfragide: Dom Quixote, 2010.

BEAUVOIR, Simone de. O segundo sexo - fatos e mitos. São Paulo: Difusão Européia do Livro, 1970.

BOURDIEU, Pierre. A dominação masculina. Rio de Janeiro: Bertrand, 2012.

BRAIDOTTI, Rosi. "El sujeto en el feminismo" in BRADOITI, R. Feminismo, diferencia sexualy subjetividade nómade. Barcelona: Editorial Gedisa, 2004.

ECO, Umberto. Obra aberta. São Paulo: Editora perspectiva, 1988.

FEMENÍAS, María Luisa. "Esbozo de un feminismo latinoamericano" in Revista Estudos Feministas. Florianópolis: Universidade Federal de Santa Catarina, 2007.

JAUSS, H. R. Pour une esthétique de la réception. Paris: Tel Gallimard, 1978.

LAGO, Mara C. de S. "Identidade: a fragmentação do conceito" in SILVA, A.; LAGO, M.; RAMOS, T. (orgs.), Falas de Gênero. Florianópolis: Ed, Mulheres, 1999. 
LAGO, Mara C. de S. "De sujeitos e identidades: diálogos entre Ciências Humanas e Psicanálise." in RIAL, C. e TONELI, M. JURACY (orgs.), Genealogias do silêncio: feminismo e gênero. Florianópolis: Editora Mulheres, 2004.

LOPES, João Teixeira. “A recepção é a arma do povo?” in Vírus, no 11. Lisboa: Bloco de Esquerda, 2010.

MCCLINTOCK, Ann. Couro imperial: raça, gênero e sexualidade no embate colonial. Campinas: Editora da Unicamp, 2010.

SANTOS, Milton. "O retorno do território". OSAL: Observatorio Social de América Latina, CLACSO, Buenos Aires, v. 6. Disponível em $<$ http://bibliotecavirtual.clacso.org.ar/ar/libros/osal/osal16/D16Santos.pdf>, 2005. RIBEIRO, Darcy (2013). O povo brasileiro. São Paulo: Companhia de Bolso.

SILVA, Tomaz T. "A produção social da identidade e da diferença" in SILVA, T. T. Identidade e Diferença: a perspectiva dos Estudos Culturais. Petrópolis, RJ: Vozes, 2000.

STOLCKE, Verena. "O Enigma das intersecções: classe, 'raça', sexo, sexualidade. A formação dos impérios transatlânticos do século XVI e XIX" in Revista Estudos Feministas. Florianópolis: Universidade Federal de Santa Catarina, 2006.

\section{Documentos audiovisuais}

The Greatest Silence: Rape in the Congo. Dirigido por Lisa F. JACKSON. HBO Films, 2007. 76 minutos. 